\title{
Shear resistance of self-stressing concrete elements expanded under 2D restraint conditions
}

\author{
Viktar Tur ${ }^{1}$, and Volha Sannikava ${ }^{1, *}$ \\ ${ }^{1}$ Brest State Technical University, 224017, Moskovskaya 267, Brest, Belarus
}

\begin{abstract}
An analytical design model for estimation the shear resistance of plane self-stressing concrete elements with orthogonal reinforcement is presented. The design model is based on the strut-and-tie model concept and takes into consideration the restrained expansion strains and selfstresses as a result of self-stressing concrete expansion. The results of theoretical investigations were finally compared to the experimental ones showing the suitability of proposed design method.
\end{abstract}

Keywords: shear resistance, plane element, expansive concrete, design model.

\section{Introduction}

The usage of expansive concrete for the reinforcement prestressing during construction of monolithic structures reveals to be an efficient manner to cover both the effectiveness in compensating early-age shrinkage and the advance on durability and serviceability characteristics. One of the key problems during the design of monolithic self-stressing concrete structures concerns the assessment of shear resistance of ones. It's noticeable that in some cases (deep beams, corbels, beam ends, diaphragms) the shear design is essential for setting the geometry and reinforcement arrangement of self-stressing concrete elements.

Strut-and-tie model is a rational approach based on the traditional truss model $[1,2]$ and used for design of reinforced concrete structures in cases when shear stresses distribute nonuniformly over the depth of concrete section. According to the strut-and-tie model concept [3-9], reinforced concrete element represents an idealized system of compressive struts, tensile ties and nodal regions. Assessment of the resistance of reinforced concrete structures follows the requirements provided in actual codes [10-14]. When performing a design of self-stressing concrete elements, strut-and-tie model should take into account the presence of initial strains and stresses caused by prestressing of reinforcement during the concrete expansion.

\footnotetext{
*Corresponding author: volhasannikava@list.ru
} 
In this paper a concept of calculation method for assessment the shear resistance of selfstressing concrete elements expanded under biaxial restraint conditions is presented. The proposed design model is based on the strut-and-tie model strategy counting for the initial strains and self-stresses as a result of self-stressing concrete expansion.

\section{Design model for assessment the shear resistance of plane self-stressing concrete elements}

Details of code requirements for design of reinforced concrete structures according to the strut-and-tie model [10-14] were compared and analysed in the authors' research papers [15-18]. It's noticeable that with respect to the resistance of tensile ties the code provisions [10-14] take into consideration stresses in both nonprestressed and prestressed reinforcement. At the same time concerning the compressive struts and node surfaces only requirements for nonprestressed elements are considered [10-14]. The experimental investigations $[15,17]$ also have shown that the most reliable provisions concerning the strut-and-tie model were presented in fib Model Code [12].

As in case of concrete elements prestressed in traditional ways (mechanical, etc.) the behavior of self-stressing concrete elements under the static load can be divided into two specific stages (Figure 1): before and after the moment of reduction the compressive stresses in concrete to zero (moment of decompression).

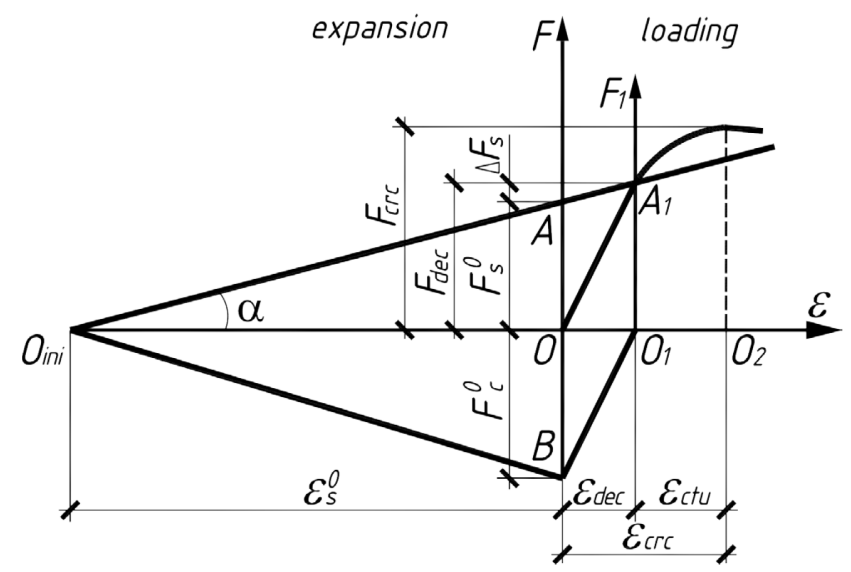

Fig. 1. Distribution of forces in self-stressing concrete elements.

In the Figure $1 F_{S}^{0}, F_{C}^{0}$ are the forces in reinforcement and concrete (section OA and OB respectively) in the principle stresses direction by the beginning of load action; $\Delta F_{S}$ is the incremental force in reinforcement in the principle stresses direction at the stage preceding the moment of decompression; $F_{d e c}$ is the decompression force in reinforcement at the moment of reduction the compressive strains in concrete to zero in the principle stresses direction; $F_{c r c}$ is the cracking force in the principle stresses direction; $\varepsilon_{S}^{0}$ is the restrained expansion strain in the principle direction by the beginning of load action; $\varepsilon_{d e c}$ is the strain in self-stressing concrete element in the principle direction at the moment of decompression; $\varepsilon_{c r c}$ is the strain in self-stressing concrete element in the principle direction under loading at the moment of cracking; $\varepsilon_{c t u}$ is the ultimate tensile strain in concrete.

The proposed design model for assessment the shear resistance of self-stressing concrete elements expanded under two-way restraint conditions differs from actual strut- 
and-tie models by taking into consideration the shear resistance at the moment of reduction the compressive strains in concrete to zero. Thus, the total shear resistance of self-stressing concrete element can be presented as follows:

$$
F_{u}=F_{u \cdot d e c}+F_{u . F}
$$

where $F_{u \text {.dec }}$ is the shear resistance at the moment of decompression;

$F_{u, F}$ is the shear resistance that is calculated as in case of nonprestressed reinforced concrete elements following the code requirements for strut-and-tie models [12].

Such a division is convenient to consider the restrained expansion strains and selfstresses as a result of self-stressing concrete expansion in the strut-and-tie model solution.

On that basis the following assumptions related to the proposed strut-and-tie model with respect to self-stressing concrete elements can be postulated:

1) a model geometry is determined from the actual stress field during the elastic behavior of concrete;

2) forces in compressive struts and tensile ties are calculated according to the static scheme of element;

3) design of compressive struts, tensile ties and nodal regions are carried out based on the theory of plasticity;

4) from the applying of load until the moment of decompression the behavior of plane self-stressing concrete element is modelled as elastic, so the traditional stress-strain relationships are valid:

- strains and stresses in concrete can be described by corresponding Mohr's circles (Figure 2a, 2b);

- directions of principle strains and principle stresses coincide (Figure 2c).
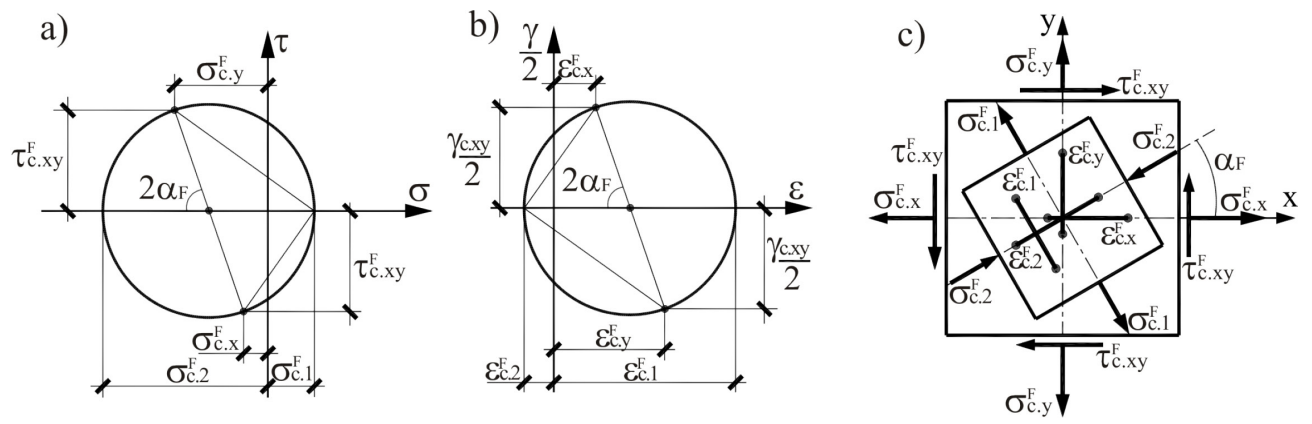

a) Mohr's circle for stresses; b) Mohr's circle for strains; c) directions of strains and stresses under static loading.

Fig. 2. Stress-strain relationship in plane self-stressing concrete element.

Calculation of resistance at the moment of decompression $F_{u \text { ude }}$ is carried out based on the statement that initial compressive strains in concrete in the direction of normal to the strut longitudinal axis as a result of prestressing $\varepsilon_{c, y \alpha}^{0}$ equal to the principal tensile strains in concrete in the direction of principle tensile stresses under the action of concenctrated load $\varepsilon_{c .1}^{F}$.

The initial compressive strains in concrete in the direction of normal to the strut longitudinal axis $\varepsilon_{c, y \alpha}^{0}$ are defined by: 


$$
\varepsilon_{c . y \alpha}^{0}=\sigma_{c . y \alpha}^{0} / E_{c m .28}
$$

where $E_{c m .28}$ is the Young's modulus of expansive concrete at the age of 28 days;

$\sigma_{c . y \alpha}^{0}$ are the initial compressive stresses in concrete in the direction of normal to the longitudinal axis of strut (or nodal surface):

$$
\sigma_{c . y \alpha}^{0}=\sigma_{c . x}^{0} \cdot \sin ^{2} \alpha+\sigma_{c . y}^{0} \cdot \cos ^{2} \alpha
$$

where $\sigma_{c . x}^{0}, \sigma_{c . y}^{0}$ are the initial compressive stresses in concrete in the orthogonal directions OX and OY respectively (it should be noted that reinforcing steel in self-stressing concrete element is located also in the orthogonal directions $\mathrm{OX}$ and $\mathrm{OY}$ );

$\alpha$ is the angle between axis of strut (or axis of nodal surface) and longitudinal axis of element.

Definition of initial compressive stresses in concrete $\sigma_{c . x}^{0}$ and $\sigma_{c . y}^{0}$ is carried out according to the modified early age strains development model for the case of two-way restraint conditions (2D MSDM) [19, 20].

The principal tensile strains in concrete in the direction of principle tensile stresses under the action of concentrated loads $\varepsilon_{c .1}^{F}$ are calculated according to expressions presented in [21]:

$$
\begin{gathered}
\varepsilon_{c .1}^{F}=\varepsilon_{c . x}^{F}+\left(\varepsilon_{c . x}^{F}-\varepsilon_{c .2}^{F}\right) \cdot \cot ^{2} \alpha \\
\varepsilon_{c . x}^{F}=\frac{M_{E d} / d_{z}+0,5 \cdot N_{E d}+0,5 \cdot V_{E d} \cdot \cot \alpha}{E_{s} \cdot A_{s}}, \\
\varepsilon_{c .2}^{F}=\frac{\sigma_{c .2}^{F}}{E_{c m .28}}=\frac{V_{E d}}{b \cdot d \cdot E_{c m .28}}(\tan \alpha+\cot \alpha) .
\end{gathered}
$$

In formulas (4-6) $\varepsilon_{c . x}^{F}$ refers to the strains of extreme tensile reinforcement or in the section at a distance of $0,6 d$ from the extreme top concrete fiber; $\varepsilon_{c .2}^{F}$ refers to the principle compressive strains in strut.

Calculation of the shear resistance $F_{u, F}$ in case of nonprestressed reinforced concrete elements is carried out according to the requirements for strut-and-tie models presented in fib Model Code 2010 [12]:

$$
F_{u . F}=f_{\max } \cdot A_{c}
$$

where $A_{c}$ is the cross-sectional area of concrete strut (or nodal surface) that is defined based on the parameters of idealized bottle-shaped strut;

$f_{\max }$ is the maximum stress at a compressive concrete strut that is calculated taking into account the decrease of concrete compressive strength due to the tensile strains in concrete utilizing the reduction factor $k_{c}$ :

$$
f_{\max }=k_{c} \cdot f_{c d}
$$

where $f_{c d}$ is the design value of concrete compressive strength. 


\section{Validation of proposed design model}

Validation of proposed design model for assessment the shear resistance of self-stressing concrete elements was carried out based on the experimental and theoretical investigations of three series of plane self-stressing concrete elements under the static loading. The plane self-stressing concrete element was performed as a part of compressive bottle-shaped strut and placed at a line between the support and point of application of concentrated load (Figure 3a). The plane specimens were under the axial concentrated static load according to the scheme in the Figure $3 b$.

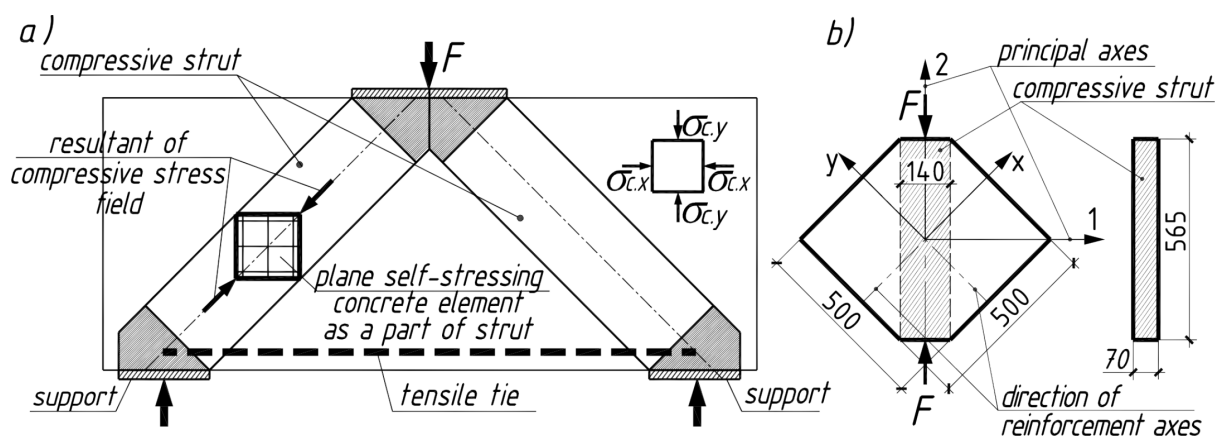

Fig. 3. Test specimen as a part of compressive strut (a) and under the concentrated load (b).

During the theoretical investigations of plane self-stressing concrete elements under the concentrated load the following parameters were calculated: the load at the moment of decompression $F_{\text {dec.calc. } \sigma}$ based on the values of initial compressive strains calculated according to the modified strain development model for the case of biaxial restraint conditions (2D MSDM) [19, 20]; the decompression load $F_{\text {dec.exp. } \sigma}$ based on the experimental values of initial compressive strains, which were determined on the plane selfstressing concrete samples by the expansive concrete stabilization; the cracking load $F_{c r c}$ based on the ultimate tensile strains in concrete which characrerizes the behavior of element from the moment of decompression to the crack formation; the total cracking load $F_{\text {crc.calc. } \sigma}^{\text {total }}$ based on the calculated values of initial compressive stresses; the total cracking load $F_{\text {crc.exp. } \sigma}^{\text {total }}$ based on the experimental values of initial compressive stresses.

It should be noticed that the total cracking load is calculated as a sum of the load at the moment of decompression and the cracking load which characterizes the behavior of element from the moment of decompression to the crack formation.

The results of investigations are presented in the Table 1 . As it could be seen from the Table 1, a good agreement arises between the experimental and calculated values of cracking load.

Table 1. Results of theoretical and experimental investigations.

\begin{tabular}{|c|c|c|c|c|c|}
\hline Series & $F_{\text {cr.calc. } \sigma}^{\text {total }}, \mathrm{kN}$ & $F_{\text {crc.exp. } \sigma}^{\text {total }}, \mathrm{kN}$ & $F_{\text {crc. } \operatorname{toxp}}^{\text {total }}, \mathrm{kN}$ & $\frac{F_{\text {crc.calc. } \sigma}^{\text {total }}}{F_{\text {crotaxp }}^{\text {tota }}}$ & $\frac{F_{\text {crc.exp. } \sigma}^{\text {total }}}{F_{\text {crc.exp }}^{\text {total }}}$ \\
\hline I & 383,44 & 382,90 & 340 & 1,127 & 1,126 \\
\hline II & 335,66 & 316,43 & 340 & 0,987 & 0,931 \\
\hline III & 278,02 & 271,41 & 300 & 0,927 & 0,905 \\
\hline
\end{tabular}




\section{Conclusions}

A strut-and-tie model for assessment the shear resistance of self-stressing concrete elements expanded under biaxial restraint conditions has been developed. The distinctive idea of the proposed model consists in considering the initial strains and stresses as a result of concrete expansion. Suitability of the model was confirmed by experimental and theoretical investigations of plane self-stressing concrete elememts under axial concentrated load.

\section{References}

1. W. Ritter, Schweizerische Bauzeitung, 33, 2 (1899)

2. E. Mörsch, Concrete-Steel Construction (McGraw-Hill, New York, 1909)

3. J. Schlaich, K. Schäfer, M. Jennewein, J. of Pr. C. Str, 32, 76 (1987)

4. J. Schlaich, K. Schäfer, IABSE congress report, 8 (1984)

5. M.D. Brown [et al.], Research Report 0-4371-2 (University of Texas, Austin, 2006)

6. C. Williams, D. Deschenes, O. Bayrak, Final Report FHWA/TX-12/5-5253-01-1 (University of Texas, Austin, 2012)

7. A. Muttoni, M. Fernandez Ruiz, F. Niketic, ACI Str. J, 112, 11 (2015)

8. M. Tyler Ley, Kyle A. Riding, Widianto, Sungjin Bae, ACI Str. J, 104, 8 (207)

9. M. D. Brown, O. Bayrak, ACI Str. J, 105, 9 (2008)

10. AASHTO LRFD Bridge Design Specifications, 8th Edition (Washington, 2017)

11. ACI Committee 318, Building Code Requirements for Structural Concrete (ACI 318 14) and Commentary (ACI 318R-14) (Farmington Hills, 2014)

12. fib Model Code 2010, Vol.1 (Federal Institute of Technology Lausanne, EPFL, Lausanne 2010)

13. PrEN 1992-1-1:2018 (Eurocode 2), Design of Concrete Structures - Part 1-1: General rules, rules for buildings, bridges and civil engineering structures (European Committee for Standardization, 2018)

14. EN 1992-1: 2001 (Eurocode 2), Design of Concrete Structures. General Rules and Rules for Building (European Committee for Standardization, 2001)

15. O. G. Sannikava, V. V. Tur, Materials of XXI PDDC, 10 (Brest, BSTU, 2018)

16. O. G. Sannikava, V. V. Tur, Vestnik PSU, Series F, 16, 10 (Novopolotsk, RIO PSU, 2018)

17. O. G. Sannikava, V. V. Tur, Vestnik PSU, Series F, 16, 6 (Novopolotsk, RIO PSU, 2018)

18. O. G. Sannikava, V. V. Tur, Materials of international academic readings "Safety of the construction fund in Russia. Problems and Solutions", 14 (Kursk, KSU, 2018)

19. V. Sannikava, V. Tur, Journal of sustainable architecture and civil engineering, 2975 86 (2017), doi: http://dx.doi.org/10.5755/j01.sace.20.3.19082

20. O. G. Sannikava, V. V. Tur, Vestnik BSTU, 1, 15 (2019)

21. V. V. Tur. A. A. Kondratchik, Design of reinforced concrete structures for shear, (Brest, BSTU, 2000) 